Research Article

\title{
Electrodeposited Benzothiazole Phthalocyanines for Corrosion Inhibition of Aluminium in Acidic Medium
}

\author{
Nnaemeka Nnaji, Njemuwa Nwaji, and Tebello Nyokong \\ Department of Chemistry, Rhodes University, Grahamstown 6140, South Africa \\ Correspondence should be addressed to Tebello Nyokong; t.nyokong@ru.ac.za
}

Received 16 May 2020; Revised 13 July 2020; Accepted 3 September 2020; Published 30 September 2020

Academic Editor: Suresh Kannan Balasingam

Copyright ( 2020 Nnaemeka Nnaji et al. This is an open access article distributed under the Creative Commons Attribution License, which permits unrestricted use, distribution, and reproduction in any medium, provided the original work is properly cited.

\begin{abstract}
Tetrakis[(benzo[d]thiazol-2-yl-thio) phthalocyaninato] gallium(III)chloride (1) and tetrakis[(benzo[d]thiazol-2ylphenoxy) phthalocyaninato] gallium(III)chloride (2) were successfully electrodeposited onto aluminium for corrosion retardation in $1.0 \mathrm{M}$ hydrochloric acid solution. The aim of this study was to compare the corrosion resistance of electrodeposited metallated phthalocyanines. Scanning electron microscopy, X-ray diffraction, electrochemical impedance spectroscopy (EIS), and polarization confirmed the aluminium corrosion inhibition potentials of complexes 1 and 2. EIS and polarization techniques showed that complex 2 performed better than complex 1, with values from EIS measurements of $82 \%$ for 1 and $86 \%$ for 2 in $1.0 \mathrm{M}$ hydrochloric acid solution. The importance of electrodeposition in industries and a dearth of research on the use of electrodeposited metallated phthalocyanines necessitated this study, and results show that coatings formed by electrodeposition of $\mathbf{1}$ and $\mathbf{2}$ onto aluminium reduced its susceptibility to corrosion attack.
\end{abstract}

\section{Introduction}

The strong electron delocalization property of metallophthalocyanines (MPcs) allow them to be used in many applications such as in nonlinear optics, dye-sensitized solar cells (DSSC), and photocatalysis and as gas sensors [1-4]. Aggregation limits the technological applications of MPcs, but this setback can be improved on (or prevented) by modifying them structurally, such as by changing the position and type of substituents [5]. Bulky substituents such as benzothiazole employed in this work reduce aggregation.

Organic molecules with $\pi$-electron systems (such as MPcs) in combination with substituents containing heteroatoms such $\mathrm{O}, \mathrm{N}$, and $\mathrm{S}$ are potential corrosion inhibitors due to their ability to adsorb on metallic surface $[6,7]$. This work therefore combines phthalocyanines with benzothiazole for synergetic corrosion inhibition and reports for the first time on the electrodeposition of phthalocyanines prior to corrosion control, as opposed to adsorption during corrosion inhibition. Phthalocyanines have been self-assembled onto electrodes for corrosion inhibition [8]. Electrodeposition employed in this work provides a homogeneous and uniform deposition of surface coating [9], and simple MPc complexes can be employed. Electrodeposition is a simple technique for electrode film (or coating) formation. Different deposition techniques include potentiodynamic (cyclic voltammetry), potentiostatic (chronoamperometry), and galvanostatic (chronopotentiometry) techniques, which influence structural properties and roughness features of coatings formed [10-12]. Cyclic voltammetry deposition technique however allows the control of the electrodeposition process, by monitoring the number of scans, and hence was employed in this work. The MPc complexes employed are tetrakis[(benzo[d]thiazol2ylphenoxy) phthalocyaninato] gallium (III) chloride (1) [12] and tetrakis[(benzo[d]thiazol-2-yl-thio) phthalocyaninato] gallium(III)chloride (2) [13].

This study reports for the first time the transition dipole moment $\left(\mu_{e}\right)$ and oscillator strength $(f)$ of complexes $\mathbf{1}$ and $\mathbf{2}$ (structure in Figure 1) from which corrosion inhibition abilities of $\mathbf{1}$ and $\mathbf{2}$ were determined. In the light of this, we 
investigated the corrosion inhibition properties (on aluminium) of electrodeposited complexes 1 and 2 .

\section{Results and Discussion}

Materials and equipment items used in this work can be found in Supplementary Materials (Available here).

2.1. Electronic Absorption and Emission Spectra. The syntheses of complexes (1) and (2) (Figure 1) have been reported [14].

Aggregation of phthalocyanines in solution is known [15], and the factors which affect this property are complexed metal ions, concentration, nature of solvent, temperature, and the substituents [16]. Aggregation is evidenced by peak broadening which is absent for complexes $\mathbf{1}$ and $\mathbf{2}$ in the studied solvents at concentrations $\leq 1.0 \times 10^{-5} \mathrm{M}$, shown in Figures S1 and S2 (Supplementary Materials). In corroboration, Lambert-Beer law was obeyed in the $1.0 \times 10^{-6} \mathrm{M}$ to $1.0 \times 10^{-5} \mathrm{M}$ concentration range. This confirms that complexes $\mathbf{1}$ and $\mathbf{2}$ are not significantly aggregated within this concentration range.

Complexes 1 and 2 showed Q bands at $689 \mathrm{~nm}$ and $692 \mathrm{~nm}$ in DMSO (Table 1). Observation from this study reveals that $\mathrm{Q}$ band maximum for $\mathbf{2}$ is red shifted compared to that for $\mathbf{1}$ (Table 1). A plausible explanation is the fact that complex 2 contains sulphur bridges between the benzothiazole moieties and the phthalocyanine core. This differs from complex 1 which has phenoxy bridge between the benzothiazole moieties and the phthalocyanine. Similar observation was earlier reported by Li and coworkers [17]. Sulphur groups are known to red shift the $Q$ band of phthalocyanines [18].

Dipole moment is the measure of polarity in a bond which is related to the distribution of electrons in a molecule; it is an index which can be used for the prediction of the magnitude/extent of a corrosion inhibition process. It is generally agreed that polar compounds possessing high dipole moments possess good adsorption properties on the metal surface leading to better corrosion inhibition efficiency [19]. Oscillator strength is related to dipole moment, and it is employed in this work to determine the possible corrosion inhibition efficiencies of complexes $\mathbf{1}$ and $\mathbf{2}$ in different solvents. Even though complexes $\mathbf{1}$ and $\mathbf{2}$ are electrodeposited, these parameters may give an idea of which complex can be a better corrosion inhibitor. Determination of oscillator strength $\left(f_{s}\right)$, transition dipole moment $(\mu)$, and integrated absorption coefficient (IAC) was performed using expressions derived elsewhere [20]:

$$
\begin{aligned}
f_{(s)} & =\frac{\left(4 \pi \varepsilon_{0}\right) c^{2} m_{e} \ln 10}{q^{2} \pi N_{0}}(\mathrm{IAC}), \\
\mu_{\mathrm{km}}^{2} & =\frac{3 h c \ln 10}{8 \pi^{2} N_{0} \bar{v}_{\max }}(\mathrm{IAC}),
\end{aligned}
$$

where

$$
\mu_{\mathrm{km}}^{2}=\left(\mu_{e}-\mu_{g}\right)^{2}
$$

where $f_{(s)}$ is the oscillator strength (in solution) and the transition dipole moment is represented by $\mu_{\mathrm{km}}$. Also, $\mu_{e}$ and $\mu_{g}$ are the dipole moments of the excited and ground states, respectively, $q$ is the charge of the electron, $\bar{v}_{\text {max }}$ (values in Table 1) represents the wavenumber of maximum absorption, $N_{0}$ is the Avogadro number, $h$ is the Planck constant, $c$ is the speed of light, $\varepsilon_{0}$ is the permittivity of free space, and $m_{e}$ is mass of electron. IAC was determined using area under the $\mathrm{Q}$ band using absorption data such that molar absorptivity $(\varepsilon)$ was plotted against the wavenumber [20]. The $\mathrm{Q}$ band maxima varies with the nature of the solvent, and hence, different solvents are used.

Table 2 presents the parameters for complexes $\mathbf{1}$ and $\mathbf{2}$ in the studied solvents, recorded in the form of oscillator strengths $\left(f_{(s)}\right)$ and transition dipole moments $\left(\mu_{\mathrm{km}}\right)$.

The ease at which complexes $\mathbf{1}$ and $\mathbf{2}$ are polarizable is implied by the positive values of transition dipole moment, derivable from equation (3), and showing that $\mu_{e}>\mu_{g}$. This in turn explains why they adsorb very well on metal surfaces resulting in good inhibition efficiencies $[12,13]$. Complex 2 has higher $\mu_{\mathrm{km}}$ and $f_{(s)}$ than complex 1 in all solvents, suggesting better corrosion inhibition for the former. However, this conclusion is tentative since complexes $\mathbf{1}$ and $\mathbf{2}$ are electrodeposited onto $\mathrm{Al}$ in this work and are not in solution.

2.2. Electrodeposition. Figure 2(a) shows the cyclic voltammogram peaks of complex $\mathbf{1}$ on GCE as an example. All peaks in Figure 2(a) are due to ring-based processes since the central metals are inactive. Complexes $\mathbf{1}$ and $\mathbf{2}$ were electrodeposited onto the $\mathrm{Al}$ by scanning from 1.0 to $-2.3 \mathrm{~V}$ vs $\mathrm{Ag} / \mathrm{AgCl}$ in dichloromethane (DCM) containing $\mathrm{TBABF}_{4}$ (Figure 2(b)). On the Al electrode, steady state behaviour is observed on the anodic side. It is the shape of the electrode that determines whether it will reach a steady state or not [21]. The peak near $-1.6 \mathrm{~V}$ increased with continuous cycling indicating that a film was formed on the electrode as a consequence of electrodeposition. Electrodeposition is judged by increase in current without shift in potential or formation of new peaks as observed in Figure 2(b) [22]. The steady state peaks only shift to more negative potentials with cycling (Figure 2(b)). The colour of the phthalocyanine solution became less intense confirming electrodeposition of the Pc from the solution to the electrode.

Figure 3 presents the thermal degradation information of benzothiazole phthalocyanines. These TGA curves show that the studied Pcs are thermally stable (before electrodeposition) at moderately high temperatures (below $300^{\circ} \mathrm{C}$ ). Detachments of the substituents probably occur at temperature ranges of $250-360^{\circ} \mathrm{C}$ and $230-370^{\circ} \mathrm{C}$ for 1 and 2 , respectively. The Pcs seem to degrade rapidly from $\sim 400^{\circ} \mathrm{C}$ for 1 and $\sim 370^{\circ} \mathrm{C}$ for 2 . Electrodeposition is not expected to change the nature of complexes $\mathbf{1}$ and 2 . The decreased stability following electrodeposition could be a result of 


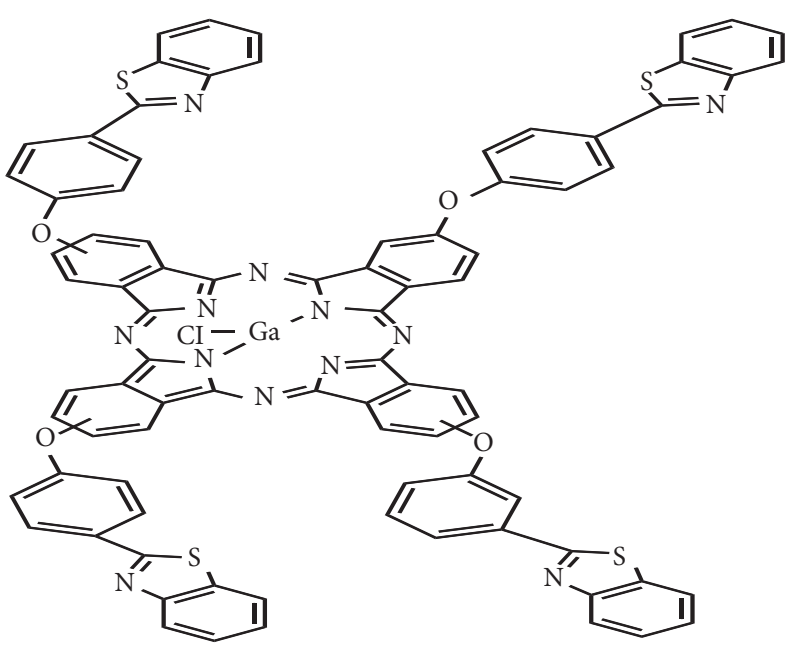

(a)

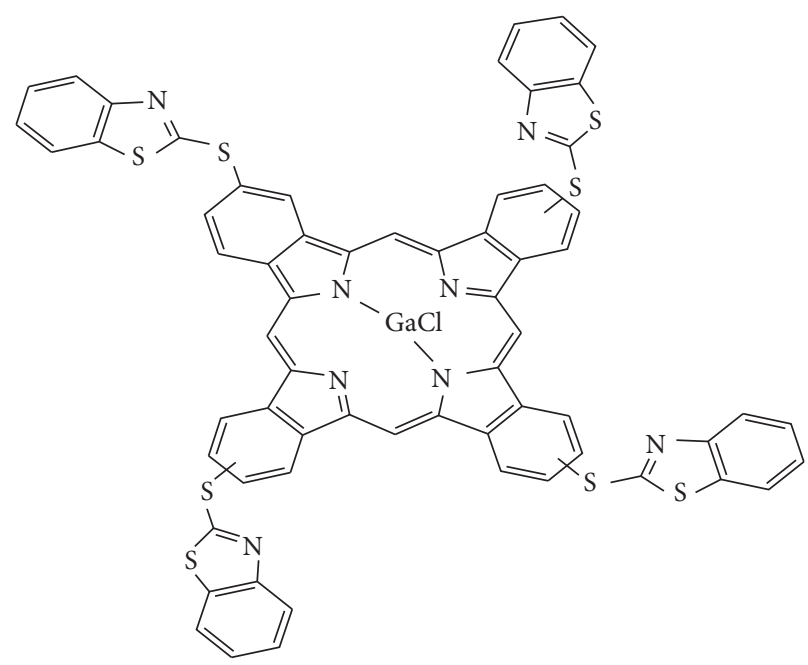

(b)

FIGURE 1: Structures of tetrakis[(4-benzo[d]thiazol-2ylphenoxy) phthalocyaninato] gallium (III) chloride (1) (a) and tetrakis[(benzo[d] thiazol-2-yl-thio) phthalocyaninato] gallium (III) chloride (2) (b) [14].

TABle 1: Absorption maxima of complexes 1 and $\mathbf{2}$ in different solvents.

\begin{tabular}{lccc}
\hline Complex & Solvent & $\lambda_{\max }(\mathrm{Q}$ band $)\left(\mathrm{cm}^{-1}\right)$ & $\lambda_{\max }(\mathrm{Q}$ band $)(\mathrm{nm})$ \\
\hline $\mathbf{1}$ & & \\
& DMSO & 14514 & 689 \\
& DMF & 14514 & 689 \\
& THF & 14493 & 690 \\
& DCM & 14388 & 695 \\
& Toluene & 14347 & 697 \\
& Benzene & 14347 & 697 \\
\hline $\mathbf{2}$ & & & \\
& DMSO & 14451 & 692 \\
& DMF & 14493 & 690 \\
& THF & 14430 & 693 \\
& DCM & 14265 & 701 \\
& Toluene & 14225 & 703 \\
Benzene & 14245 & 702 \\
\hline
\end{tabular}

TABle 2: Transition dipole moment and oscillator strength for complexes 1 and 2.

\begin{tabular}{lcccc}
\hline & \multicolumn{2}{c}{$\mu_{\mathrm{km}}(\mathrm{D})$} & \multicolumn{2}{c}{$f(s)$} \\
& $\mathbf{1}$ & $\mathbf{2}$ & $\mathbf{1}$ & $\mathbf{2}$ \\
\hline DMSO & 1.746 & 2.268 & 0.136 & 0.386 \\
DMF & 1.864 & 2.027 & 0.179 & 0.206 \\
THF & 2.014 & 2.452 & 0.240 & 0.528 \\
DCM & 1.872 & 1.939 & 0.176 & 0.246 \\
Toluene & 1.356 & 1.641 & 0.049 & 0.106 \\
Benzene & 1.871 & 2.122 & 0.179 & 0.296 \\
\hline
\end{tabular}

change in conformation during the electrodeposition process [23]. Thermograms obtained after $\mathrm{HCl}$ exposure are similar with those recorded for electrodeposited complexes 1 and 2 before corrosion.

\subsection{Corrosion Inhibition}

2.3.1. Surface Morphology-Scanning Electron Microscopy (SEM). Scanning electron microscopy (SEM) was used for the study of surface morphology [24] (Figure 4). The smooth $\mathrm{Al}$ surface becomes badly battered after immersion in $1.0 \mathrm{M}$ hydrochloric acid solution as shown in Figure 4(b). Figure 4(c) shows the SEM image of electrodeposited-2, before immersion in $\mathrm{HCl}$. An amorphous surface with intrinsic plateletlike flakes covering the metal surface is observed. The electrodeposited-2 covering strongly adheres to the metal surface such that even after exposure to the corrosive medium, the metal is protected from acid attack as Figure 4(d) shows. This is judged by the similarities of the images of the electrodeposited-2 before and after immersion in acid, showing that the observed surface is that of the phthalocyanine and not the metal. The aluminium coated with electrodeposited-1 possesses flowerylike flakes (Figure 4(e)) which adhere strongly onto the metal, protecting it from the corrosive attack of $1.0 \mathrm{M}$ hydrochloric acid as seen in Figure 4(f). However, the image of electrodeposited-1 after being immersed in acid is different from that before, suggesting less protection compared to electrodeposited-2. The electrodeposited aluminium surfaces of Figures 4(c) and 4(e) became more dense and rough necessitated by the formation of films, which in turn protected the metal from exposure to aggressive environments. This observation is in agreement with earlier findings [25]. Amorphous and crystalline surfaces of electrodeposited benzothiazoles have been reported earlier [26].

2.3.2. $X R D$. Literature sources [27-30] earlier reported that diffraction peaks of uncorroded $\mathrm{AI}$ are due to alumina $\left(\mathrm{Al}_{2} \mathrm{O}_{3}\right)$, bayerite $\left[\alpha-\mathrm{Al}(\mathrm{OH})_{3}\right]$, boehmite [AlO $\left.(\mathrm{OH})\right]$, gibbsite $\left[\gamma-\mathrm{Al}(\mathrm{OH})_{3}\right]$, and metastable alumina $\left(\chi-\mathrm{Al}_{2} \mathrm{O}_{3}\right.$ and $\kappa-\mathrm{Al}_{2} \mathrm{O}_{3}$ ) which are observed in this study at $2 \theta=39.3$, 


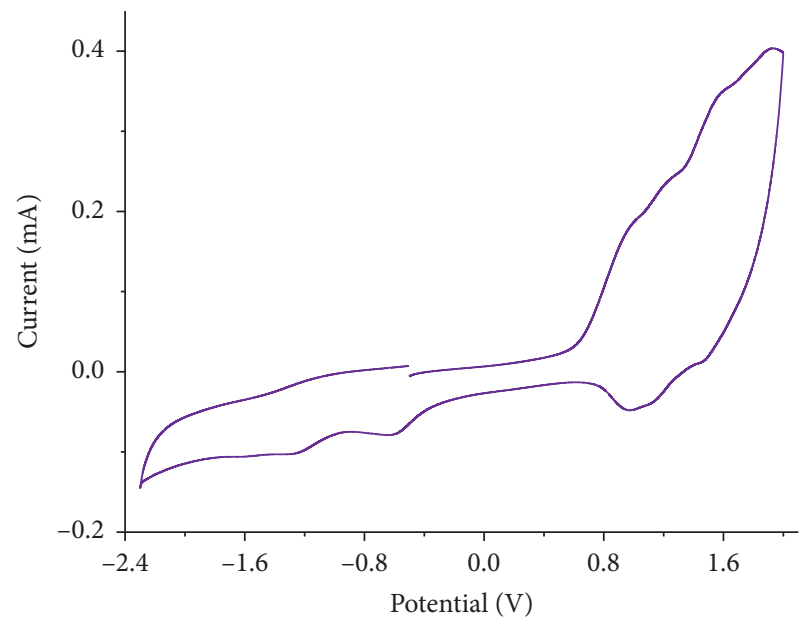

(a)

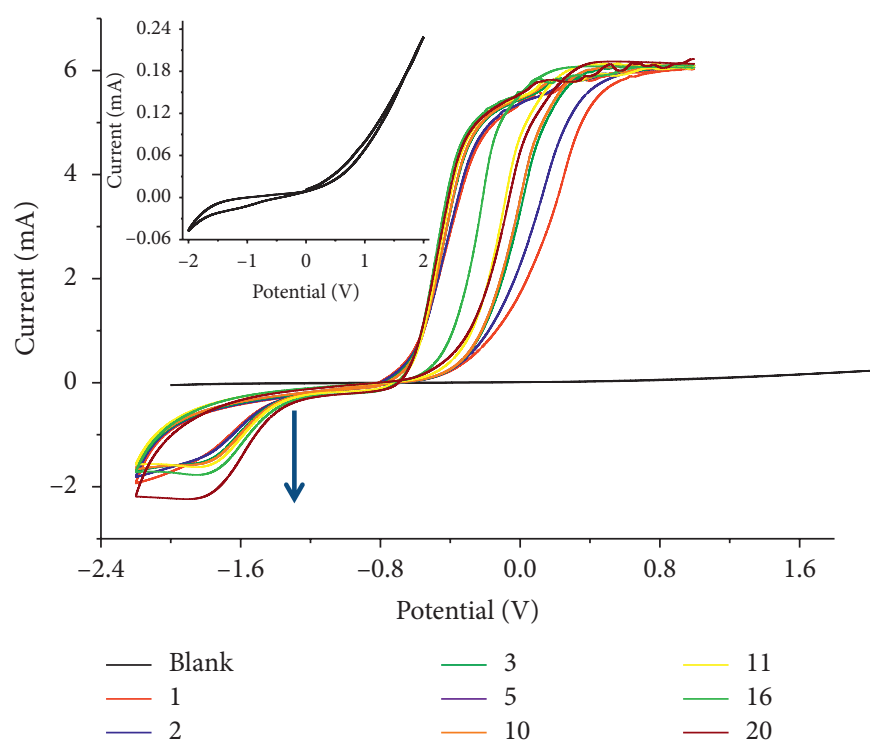

(b)

Figure 2: (a) Cyclic voltammogram of complex 1 in DCM containing $0.1 \mathrm{~mol} \cdot \mathrm{dm}^{-3} \mathrm{TBABF}_{4}$ at scan rate $=100 \mathrm{mV} / \mathrm{s}$, concentration $\sim 1 \times 10^{-4} \mathrm{~mol} \cdot \mathrm{dm}^{-3}$, and electrode $=$ glassy carbon. (b) Evolution of the cyclic voltammograms of complex 2 in DCM containing $0.1 \mathrm{~mol} \cdot \mathrm{dm}^{-3} \mathrm{TBABF}_{4}$ during repeated successive scans (only 8 scans are shown), scan rate $=100 \mathrm{mV} / \mathrm{s}$, concentration $\sim 1 \times 10^{-4} \mathrm{~mol} \cdot \mathrm{dm}^{-3}$, and electrode $=\mathrm{Al}$ coupon. Inserted is the cyclic voltammogram of blank (without complex 2).

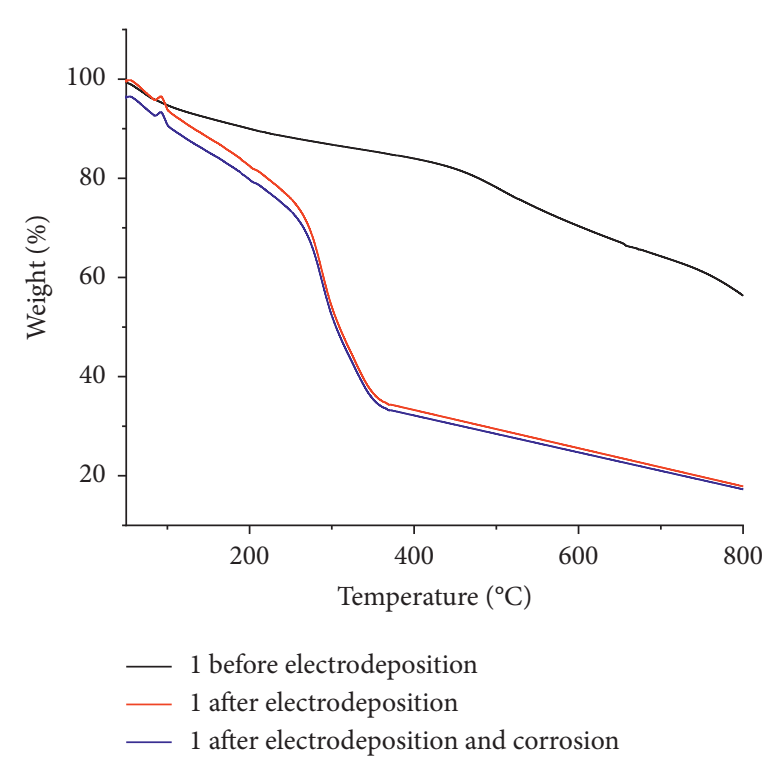

(a)

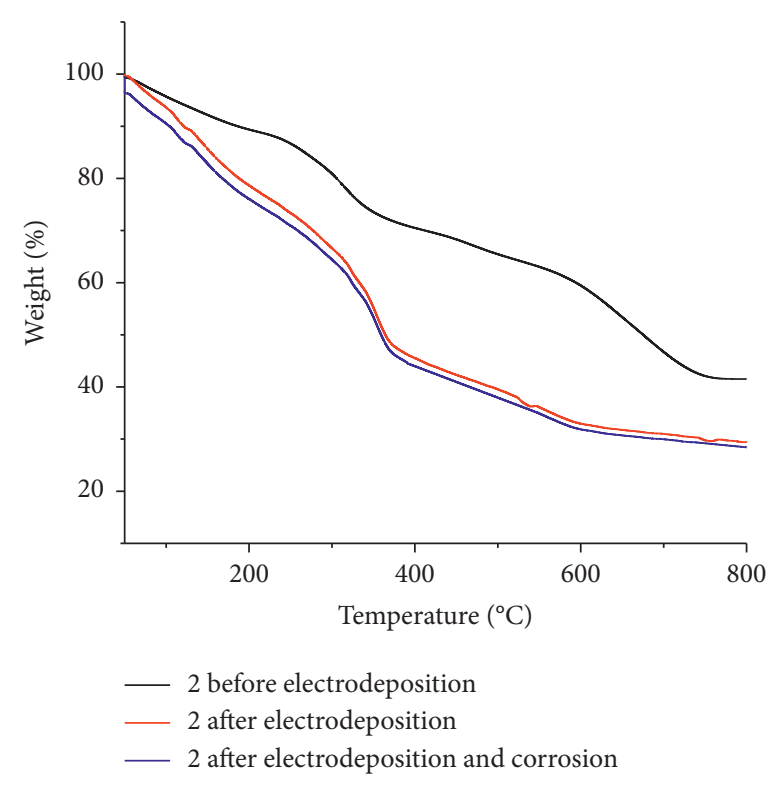

(b)

FIgURE 3: Thermogravimetric curves of phthalocyanine derivatives 1 (a) and 2 (b) before and after electrodeposition, heated at $20^{\circ} \mathrm{C}$ min ${ }^{-1}$ from 50 to $800^{\circ} \mathrm{C}$ in nitrogen.

$45.5,65.8,78.8$, and $83.1^{\circ}$ (Figure 5). For the corroded Al, the peak at $39.3^{\circ}$ is less intense and the one at $78.8^{\circ}$ increases in intensity (Figure 5). Following protection with the coatings (electrodeposited-1 and electrodeposited-2), the peak at $78.8^{\circ}$ is low in intensity (relative intensity $18.1 \%$ and $28.4 \%$, respectively) almost to the level of uncorroded $\mathrm{Al}$ (at $17.8 \%$ relative intensity). The peak near $2 \theta=45.0^{\circ}$ has increased with $100 \%$ relative intensities (Table 3 ) for $\mathbf{1}_{\text {corr }}$ and $\boldsymbol{2}_{\text {corr }}$ compared to uncoated aluminium surface (at $9.8 \%$ relative intensity); this increase corroborates with corrosion protection by electrodeposited-1 and electrodeposited-2. Seifzadeh et al. [31] associated increase in XRD peaks in the presence of corrosion inhibitors with reduced corrosion. This probably suggests there was some corrosion of the metal before electrodeposition in this work. There is a drastic decrease of the peak at $2 \theta=65.8^{\circ}$, and such changes have 


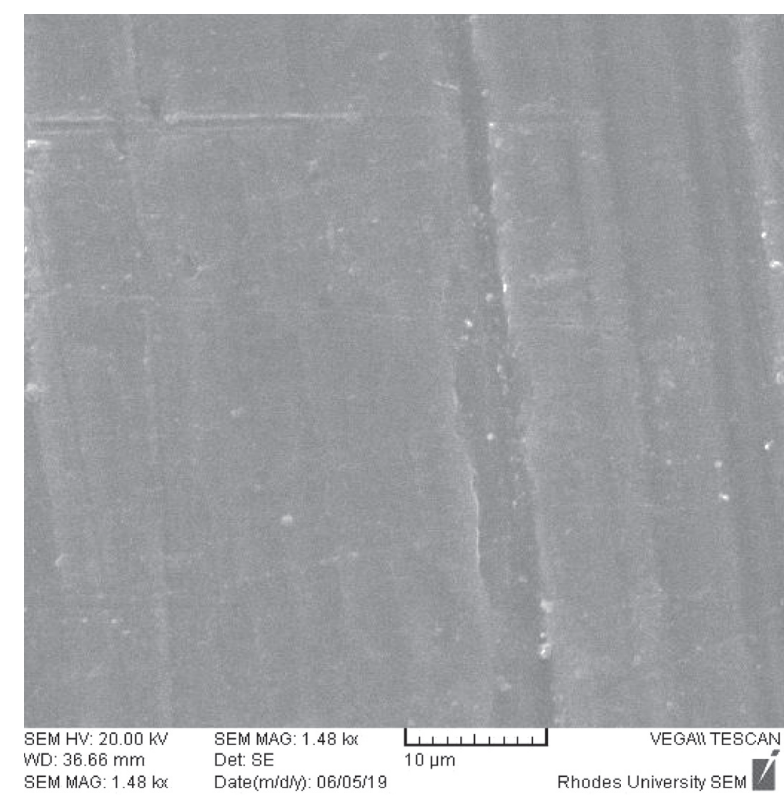

(a)

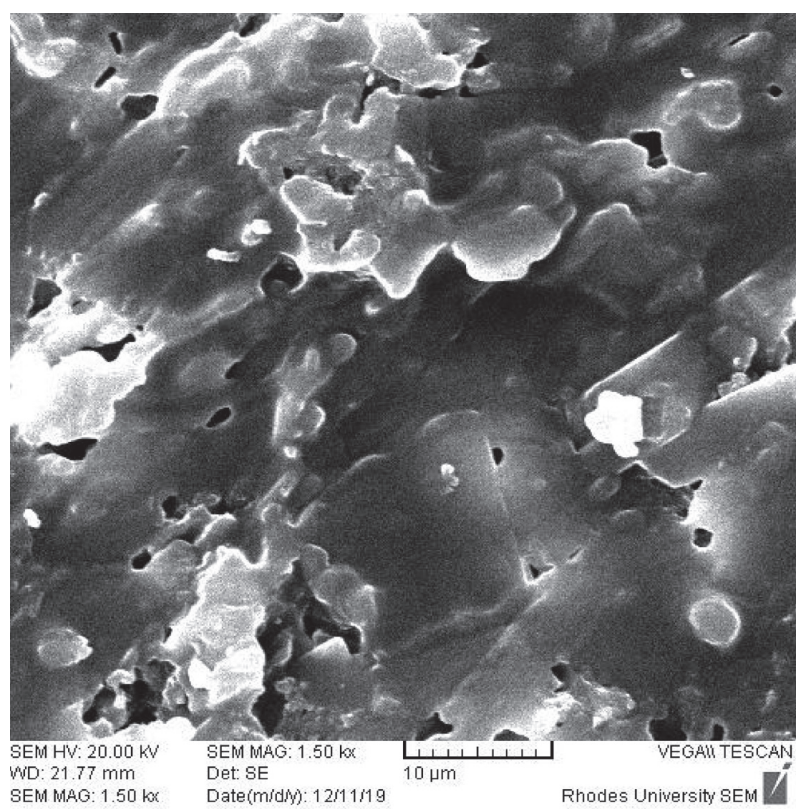

(c)

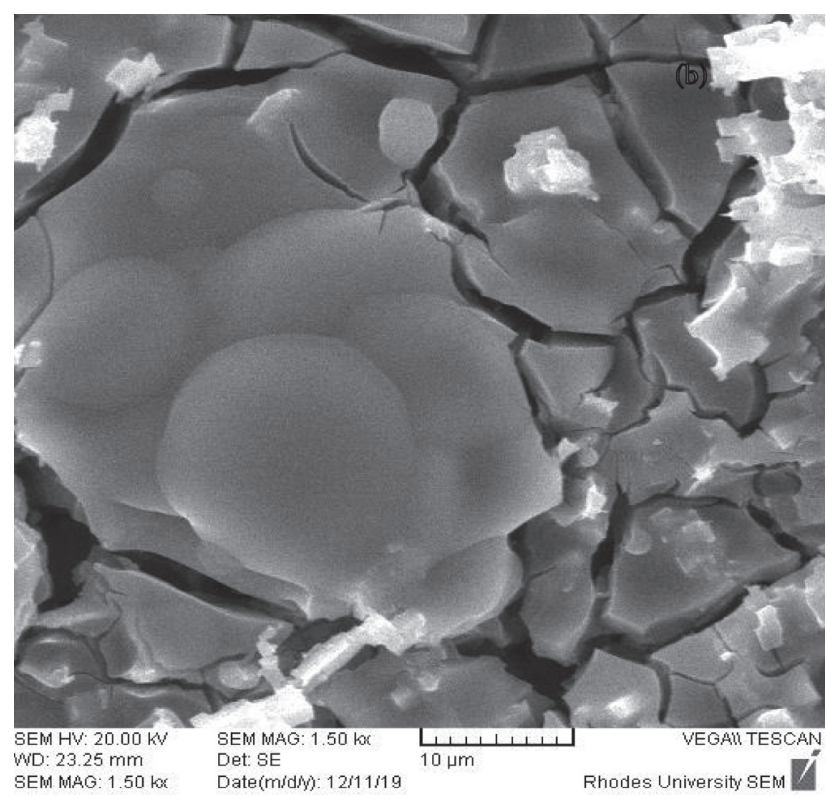

(b)

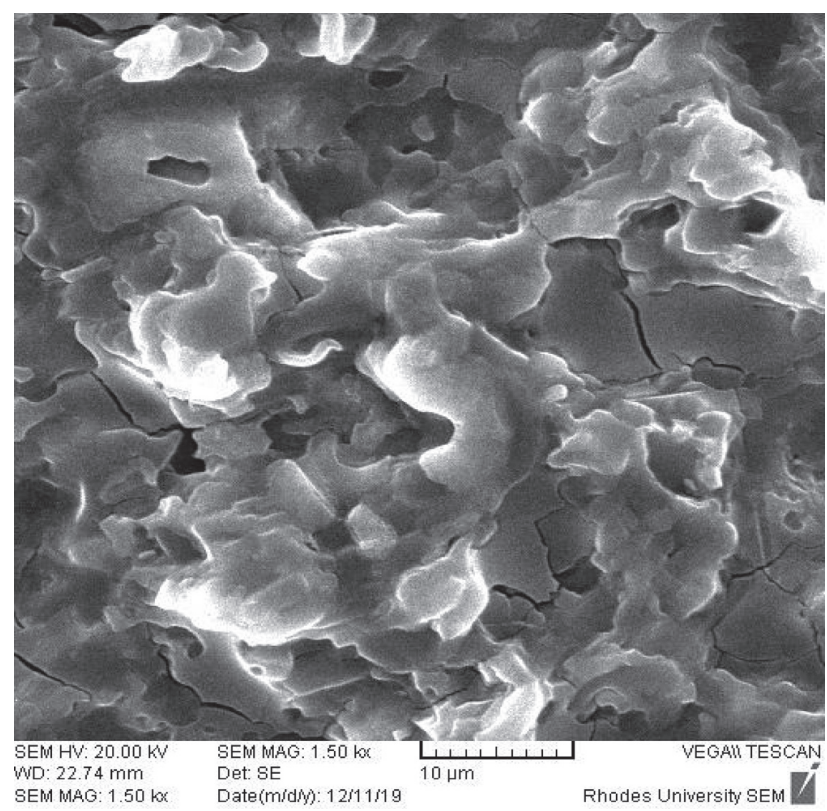

(d)

Figure 4: Continued. 


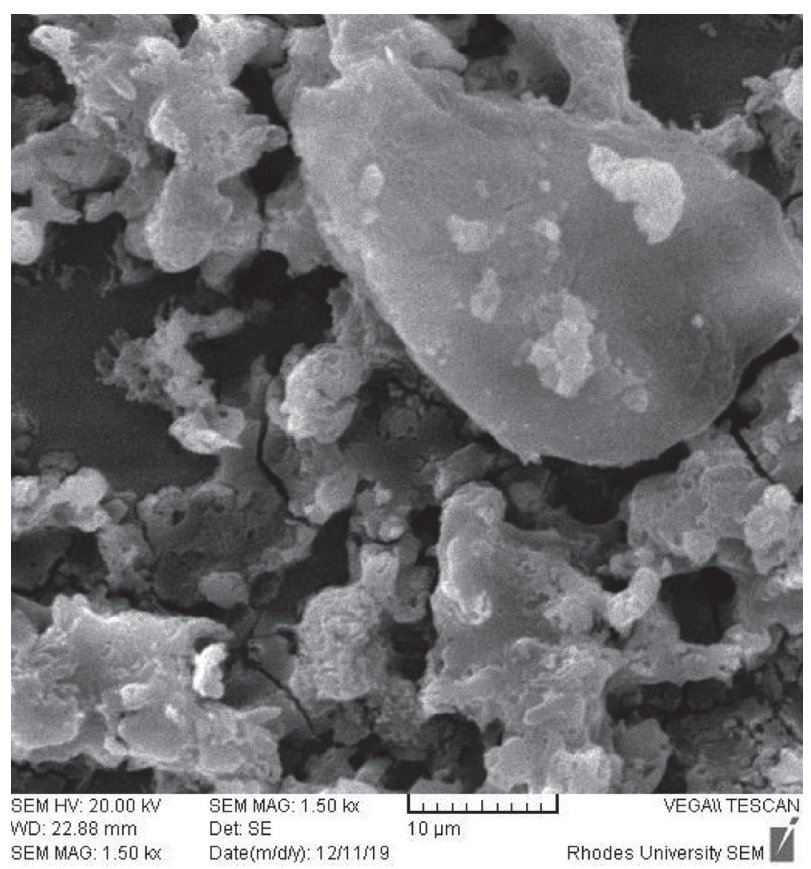

(e)

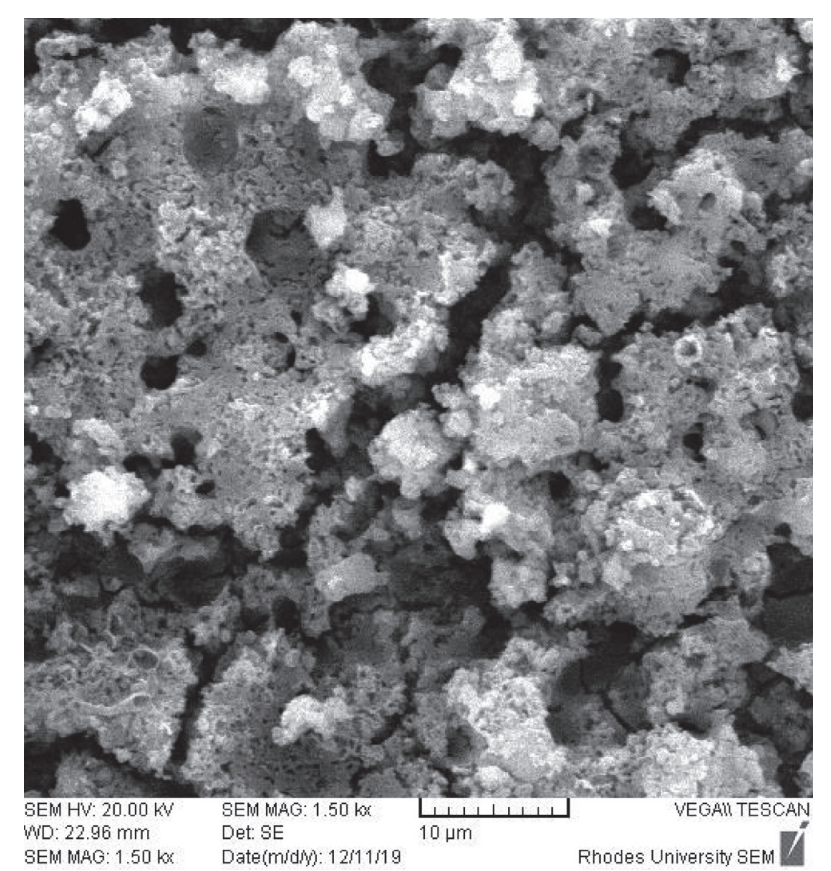

(f)

Figure 4: SEM of aluminium alone before (a) and after (b) corrosion. Electrodeposited-2 before (c) and after (d) immersion in $\mathrm{HCl}$ and electrodeposited-1 before (e) and after (f) immersion in $\mathrm{HCl}$.

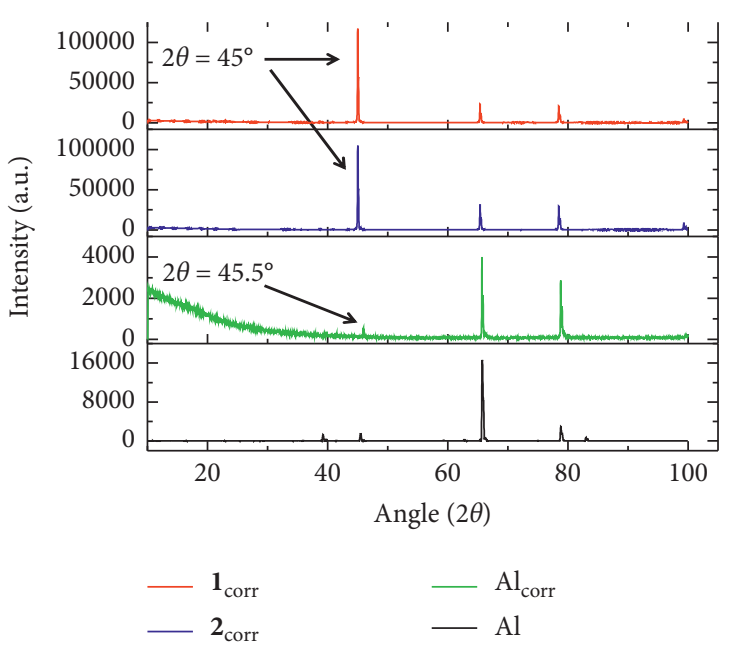

Figure 5: X-ray diffraction of aluminium (before and after corrosion) and $\mathrm{Al}$ after scrapping of electrodeposited phthalocyanines following corrosion (represented as $\mathbf{1}_{\text {corr }}$ and $\mathbf{2}_{\text {corr }}$ ).

been attributed to the possible complex formation between the metal and the inhibitor molecule [32].

\subsubsection{Electrochemical Impedance Spectroscopy (EIS).} Uncoated aluminium and that coated via electrodeposition of complexes 1 and 2 when immersed in $1.0 \mathrm{M}$ hydrochloric acid solution gave Nyquist plots and phase angle-log (frequency) diagrams, presented in Figure 6. It was observed that the uncoated metal exhibited capacitive and inductive
TABLE 3: XRD absolute and relative intensity values.

\begin{tabular}{lccc}
\hline & $\begin{array}{c}\text { Absolute } \\
\text { intensity }\end{array}$ & $\begin{array}{c}\text { Relative intensity } \\
(\%)\end{array}$ & $\begin{array}{c}2 \theta \text { values } \\
\text { (degree) }\end{array}$ \\
\hline \multirow{4}{*}{$\mathbf{1}_{\text {corr }}$} & 116,999 & 100.0 & 45.0 \\
& 23,439 & 20.0 & 65.8 \\
& 21,130 & 18.1 & 78.8 \\
& 4,574 & 3.9 & 99.7 \\
\hline \multirow{2}{*}{$\mathbf{2}_{\text {corr }}$} & 104,762 & 100.0 & 45.0 \\
& 31,270 & 29.4 & 65.8 \\
& 29,723 & 28.4 & 78.8 \\
\multirow{4}{*}{$\mathrm{Al}_{\text {corr }}$} & 8549 & 8.2 & 99.7 \\
& 561 & 14.0 & 45.5 \\
& 4003 & 100.0 & 65.8 \\
& 2853 & 71.3 & 78.8 \\
& 227 & 5.8 & 99.6 \\
\hline \multirow{4}{*}{$\mathrm{Al}$} & 1273 & 7.6 & 39.3 \\
& 1634 & 9.8 & 45.5 \\
& 16656 & 100.0 & 65.8 \\
& 2958 & 17.8 & 78.8 \\
& 695 & 4.2 & 83.1 \\
\hline
\end{tabular}

curves at high- and low-frequency values, respectively. On the contrary, the coated metal with the MPcs gave electrochemical signals which showed capacitive curves, followed by a Warburg diffusional tail which, as Ozyilmaz et al. [33] opined, is related to diffusion of corrosive species through the coating and the oxide layers. Figure 6(a) shows larger capacitive curves for coated surfaces, an indication that coating the metal causes an increase in the impedance of the inhibited substrate. Adsorption onto the electrode surface by species such as $H_{\text {ads }}^{+}$perhaps due to the relaxation 

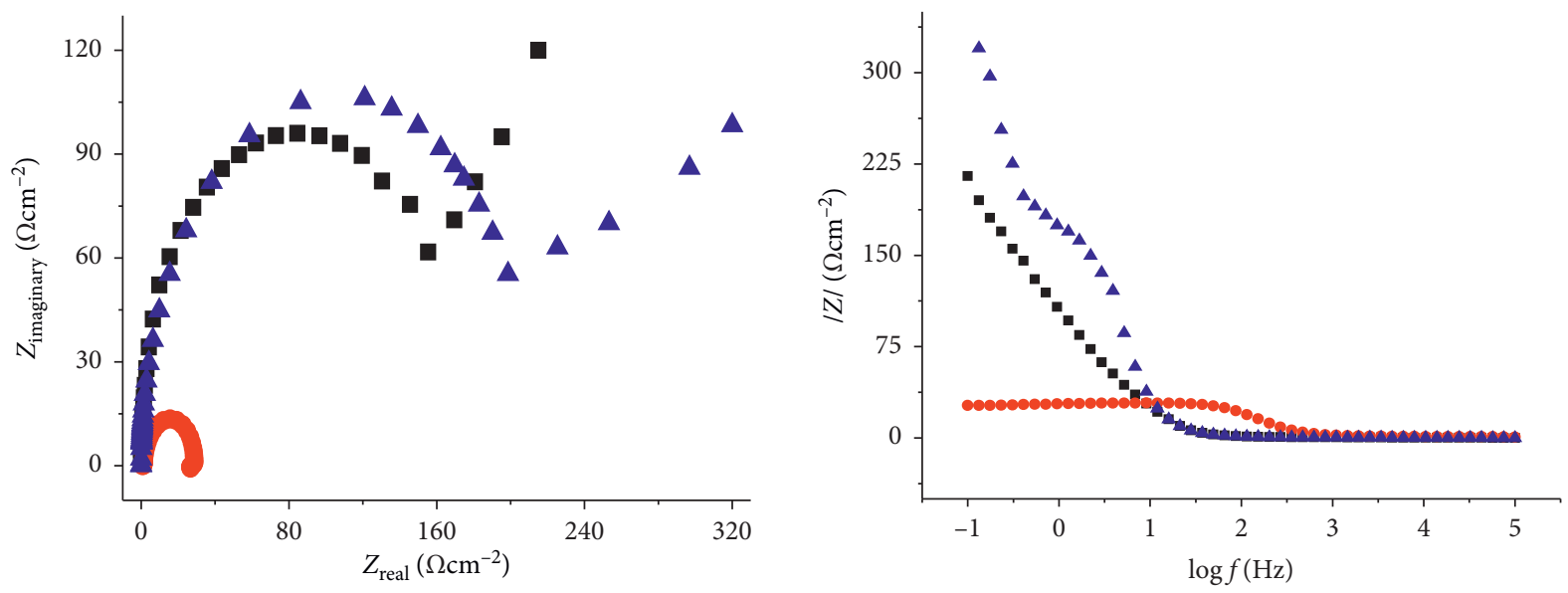

- $\mathbf{1}_{\text {corr }}$
Uncoated
- $\mathbf{2}_{\text {corr }}$

(a)

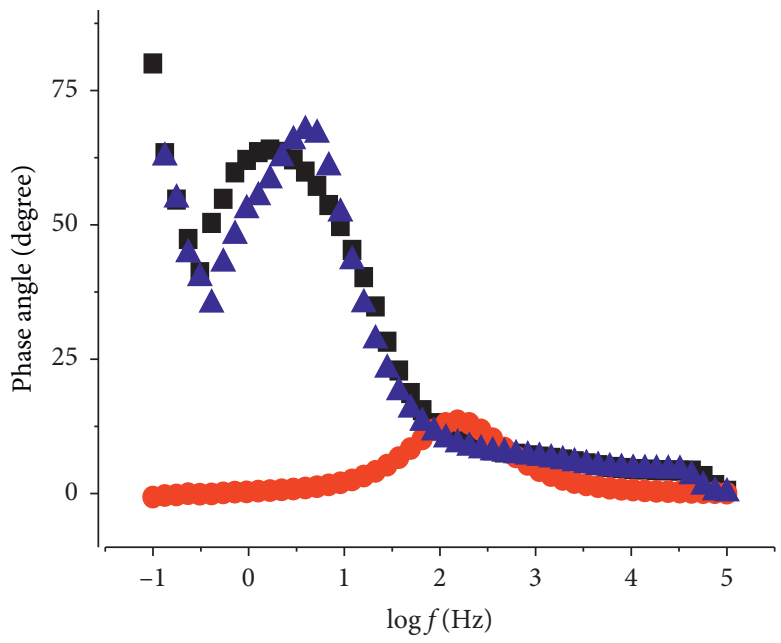
- $\mathbf{1}_{\text {corr }}$
- Uncoated
A $\mathbf{2}_{\text {corr }}$

(b)

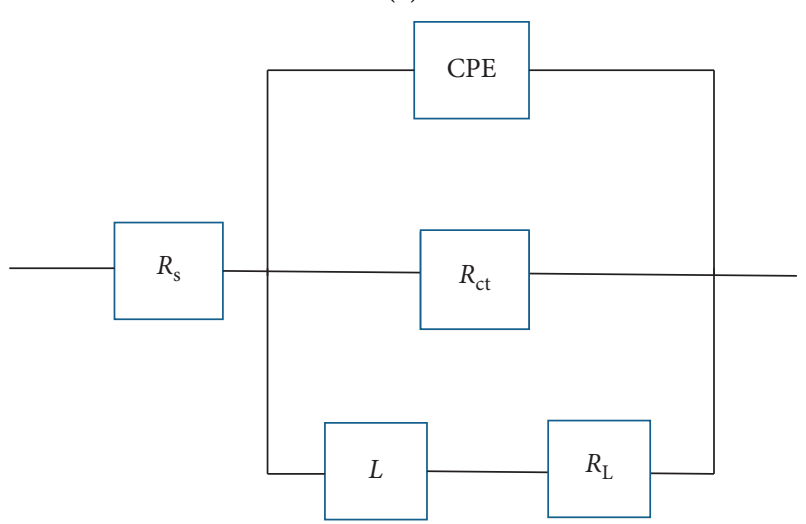

- $\mathbf{1}_{\text {corr }}$

- Uncoated

- $\mathbf{2}_{\text {corr }}$

(c)

(d)

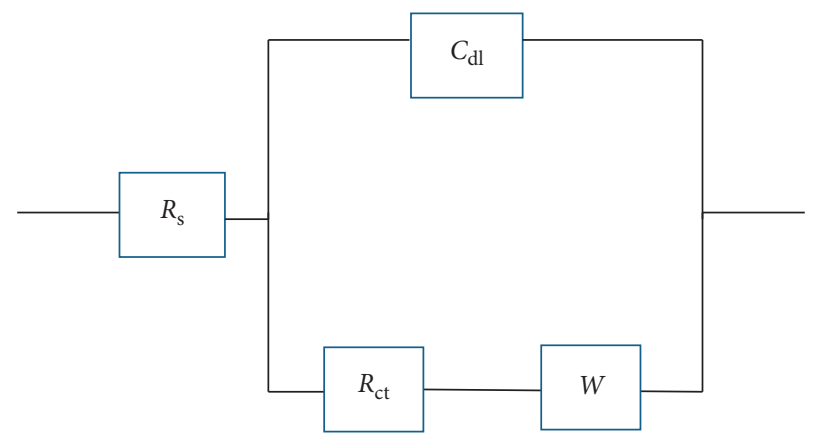

(e)

FIGURE 6: EIS data for aluminium in 1.0 M hydrochloric acid solution in the presence of electrodeposited-1 and electrodeposited-2 coatings (represented as $\mathbf{1}_{\text {corr }}$ and $\mathbf{2}_{\text {corr }}$, respectively) and without coating. (a) Nyquist plots and Bode plots, (b) $\log Z$ vs. $\log f$, and (c) phase angle ( $f$ ) vs. $\log f$. (d, e) Equivalent circuits used to fit EIS data for uncoated aluminium and coated aluminium, respectively. 
TABle 4: EIS data in $1.0 \mathrm{M} \mathrm{HCl}$.

\begin{tabular}{lcc}
\hline & $R_{\mathrm{ct}}\left(\Omega \cdot \mathrm{cm}^{2}\right)$ & IE\% \\
\hline Blank (uncoated Al) & $27.2 \pm 3.1$ & 0.0 \\
$\mathbf{1}_{\text {corr }}$ & $152 \pm 4.4$ & $82.1 \pm 2.6$ \\
$\mathbf{2}_{\text {corr }}$ & $197 \pm 8.4$ & $86.1 \pm 0.1$ \\
\hline
\end{tabular}
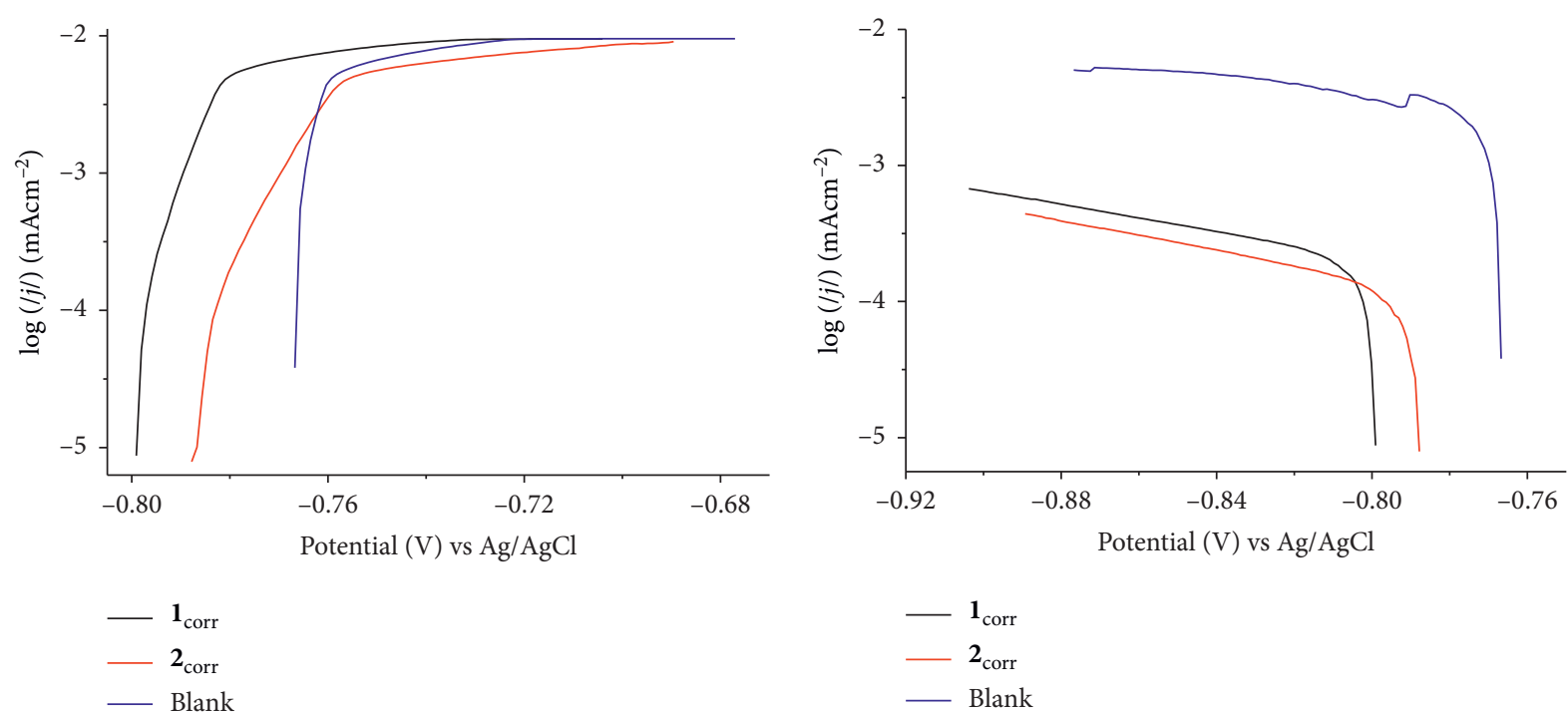

(a)

(b)

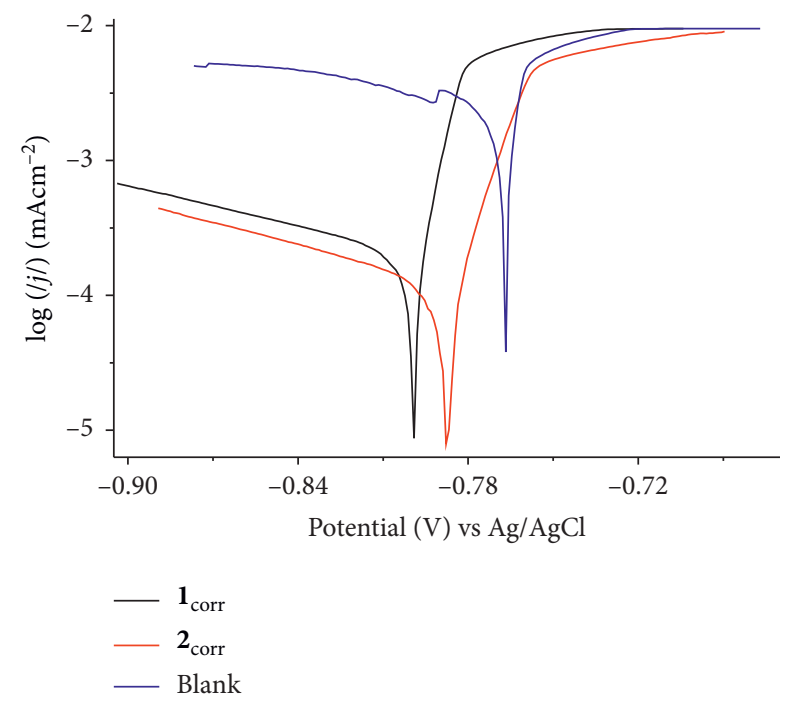

(c)

Figure 7: Anodic (a) and cathodic (b) branches and polarization curves (c). $\mathbf{1}_{\text {corr }}$ and $\mathbf{2}_{\text {corr }}$, respectively, are for coated aluminium with electrodeposited-1 and electrodeposited-2 immersed in 1.0 M hydrochloric acid solution for 30 min period and at room temperature $28^{\circ} \mathrm{C} \pm 0.05^{\circ} \mathrm{C}$

process explains the inductive curve at low-frequency values for the uncoated metal [34].

The equivalent circuit for uncoated metal, shown in Figure 6(d), consists of the following elements: the solution resistance $\left(R_{s}\right)$, charge transfer resistance $\left(R_{\mathrm{ct}}\right)$, and constant phase element (CPE), while the inductive resistance $\left(R_{L}\right)$ and inductance $(L)$ are introduced to simulate the inductive curve. Analyses of the impedance data for coated metal were performed using an equivalent circuit as shown in Figure 6(e) with the following elements: the solution resistance $\left(R_{s}\right)$, double layer capacitance $\left(C_{\mathrm{dl}}\right)$, charge transfer resistance $\left(R_{\mathrm{ct}}\right)$, and Warburg impedance element (W).

The EI\% values calculated using equation S1 in Supplementary Materials are higher for complex 2 than for complex 1 (Table 4) as predicted by transition dipole 
TABle 5: Polarization parameters for coated and uncoated aluminium in $1.0 \mathrm{M}$ hydrochloric acid.

\begin{tabular}{lcccc}
\hline Metal & $-E_{\text {corr }}(\mathrm{mV})$ & $j_{\text {corr }}\left(\mu \mathrm{Acm}^{-2}\right)$ & $-\beta_{c}\left(\mathrm{mVdec}^{-1}\right)$ & $\beta_{a}\left(\mathrm{mVdec}^{-1}\right)$ \\
\hline $\mathrm{Al}_{\text {uncoated }}$ & 767 & 749.75 & 109.86 & 310.05 \\
$\mathbf{1}_{\text {corr }}$ & 799 & 97.11 & 10.54 & 80.93 \\
$\mathbf{2}_{\text {corr }}$ & 788 & 90.09 & 3.56 & 84.00 \\
\hline
\end{tabular}

$\mathbf{1}_{\text {corr }}$ and $\mathbf{2}_{\text {corr }}$, respectively, are for coated aluminium with electrodeposited-1 and electrodeposited-2 immersed in $1.0 \mathrm{M}$ hydrochloric acid solution for $30 \mathrm{~min}$ period.

moment $\left(\mu_{e}\right)$ and oscillator strength $(f)$ discussed above. The value of $R_{\mathrm{ct}}$ is a measure of electron transfer across the exposed area of the metal surface, and it is inversely proportional to the rate of corrosion [35]. Thus, large $R_{\mathrm{ct}}$ (and IE $\%)$ values are associated with slower corroding process [36]. The $R_{\mathrm{ct}}$ values of the coated metal are about six times higher for electrodeposited-1 and seven times higher for electrodeposited-2 than the uncoated metal when immersed in the corrosive solution for $30 \mathrm{~min}$. This confirms that electrodeposited coating provides strong corrosion protections for the metal. Similar analogy was reported by $\mathrm{Lu}$ and coworkers [37]. The values of inhibition efficiency calculated from EIS are in good agreement with those determined from polarization curves in Figure 6.

Bode modulus and phase angle plots are presented in Figures 6(b) and 6(c) for coated and uncoated aluminium in 1.0 M hydrochloric acid solution. Figure 6(b) shows an increase of absolute impedance at low frequencies in Bode modulus for coated metal which confirms the higher protection and corresponds to the adsorption of the MPcs on the metal surface. Lavanya and coworkers [38] reported similar trend for metal corrosion protection by adsorbing inhibitor molecules onto the metal surface. The capacitive or resistive behaviour of an electrochemical system is provided by the Bode plots. Plots of $\log |Z|$ vs. $\log f$ at intermediate frequencies gave slope values of -0.999 (uncoated), -1.017 $\left(\mathbf{1}_{\text {corr }}\right)$, and $-0.350\left(\mathbf{2}_{\text {corr }}\right)$, with phase angle values for uncoated $\left(-13.5^{\circ}\right), \mathbf{1}_{\text {corr }}\left(-64.0^{\circ}\right)$, and $\mathbf{2}_{\text {corr }}\left(-67.5^{\circ}\right)$. These responses characterize nonideal capacitive behaviour at intermediate frequencies considering that ideal capacitive behaviour would result in a slope of -1 and a phase angle of $-90^{\circ}$. Phase angle values closer to $-90^{\circ}$ suggest that the protective films are pseudo-capacitive [39].

2.3.4. Polarization. Figures $7(\mathrm{a})$ and $7(\mathrm{~b})$ show anodic and cathodic branches of polarization curves for uncoated aluminium and aluminium coated with the MPcs and immersed in $1.0 \mathrm{M}$ hydrochloric acid solution. Figure 7 shows slight difference in the shape and slope of anodic/cathodic branches, and there is a shift in potential when the aluminium surface is coated with the Pcs and immersed in hydrochloric acid solution.

Classification of an inhibitor as predominantly anodic or cathodic is determined by the difference in corrosion potential $\left(E_{\text {corr }}\right)$ of more than $85 \mathrm{mV}$ when compared to the corrosion potential of the blank [40]. The indication that electrodeposited-1 and electrodeposited-2 possess mixed-type character is based on the fact that the differences in the corrosion potential values are all less than
$85 \mathrm{mV}$ compared to the blank (Table 5), which is indicative of possible retardation of anodic and cathodic aluminium corrosion processes [13]. Electrodeposited-1 and electrodeposited-2 exhibit predominant cathodic characters because values of cathodic Tafel slopes $\left(\beta_{c}\right)$ are more positive than in their absence, as shown in Table 5. Values of corrosion current density $\left(j_{\text {corr }}\right)$ decreased for aluminium electrodeposited-1 and electrodeposited-2 surfaces when compared to the uncoated metal surface (Table 5). This observed decrease plausibly is due to corrosion protection of the metal from attack of $\mathrm{Cl}^{-}$, indicating that the electrodeposited phthalocyanines possess good corrosion inhibition properties. Similar trend was reported for electropolymerized polyaniline and its copolymer on carbon steel [41]. The inhibition efficiency (IE\%) values were calculated using the corrosion current densities without coating and with coating (equation S2 in Supplementary Materials). The values of these parameters are shown in Table 5. IE\% is larger for $\mathbf{2}$ as was the case for the data from EIS.

\section{Conclusions}

Gallium(III) chloride phthalocyanines complexes (1) and (2) were successfully electrodeposited on aluminium metal surface by cyclic voltammetry and used as anticorrosive coatings. The coated aluminium surfaces exhibited good corrosion resistance in comparison with uncoated $\mathrm{Al}$ substrate, as demonstrated by results from EIS and potentiodynamic polarization techniques in $1.0 \mathrm{M}$ hydrochloric acid solution such that complex 2 was found to show higher inhibition efficiency than complex $\mathbf{1}$. This work has developed an efficient strategy for aluminium corrosion protection with good inhibition efficiency.

\section{Data Availability}

The data used to support the findings of this study are available from the corresponding author upon request.

\section{Disclosure}

The funders had no role in the design of the study; in the collection, analyses, or interpretation of data; in the writing of the manuscript, or in the decision to publish the results.

\section{Conflicts of Interest}

The authors declare no conflicts of interest. 


\section{Acknowledgments}

This work was supported by the Department of Science and Technology (DST) and National Research Foundation (NRF), South Africa, through the DST/NRF South African Research Chairs Initiative for Professor of Medicinal Chemistry and Nanotechnology (UID 62620) as well as the Rhodes University/DST Centre for Nanotechnology Innovation, South Africa.

\section{Supplementary Materials}

Electrodeposited benzothiazole phthalocyanines for corrosion inhibition of aluminium in acidic medium. Figure S1: absorption spectra of complex $\mathbf{1}$ in various solvents at different concentrations of $1.0 \times 10^{-6}-1.0 \times 10^{-5} \mathrm{M}$. Figure S2: absorption spectra of complex 2 in various solvents at different concentrations of $1.0 \times 10^{-6}-1.0 \times 10^{-5} \mathrm{M}$. (Supplementary Materials)

\section{References}

[1] M. A. Díaz-García, "Nonlinear optical properties of phthalocyanines and related compounds," Journal of Porphyrins and Phthalocyanines, vol. 13, no. 04n05, pp. 652-667, 2009.

[2] L.-N. Yang, Z.-Z. Sun, S.-L. Chen, and Z.-S. Li, "Iodinated $\mathrm{Al}^{\mathrm{III}}$-based phthalocyanines are promising sensitizers for dyesensitized solar cells; a theoretical comparison between $\mathrm{Zn}^{\mathrm{II}}$, $\mathrm{Mg}^{\mathrm{II}}$, and $\mathrm{Al}^{\mathrm{III}}$-based phthalocyanine sensitizers," ChemPhysChem, vol. 15, no. 3, pp. 458-466, 2014.

[3] M. K. Rana, M. Sinha, and S. Panda, "Gas sensing behavior of metal-phthalocyanines: effects of electronic structure on sensitivity," Chemical Physics, vol. 513, pp. 23-34, 2018.

[4] A. A. Kamiloglu, E. T. Saka, and I. Acar, "Substituted Co (II) and $\mathrm{Cu}$ (II) metallophthalocyanines from new Schif base containing pyrrole units: synthesis, characterization and investigation of photocatalytic activity on 2, 3-dichlorophenol oxidation," Journal of Inclusion Phenomena and Macrocyclic Chemistry, vol. 96, no. 55-65, 2020.

[5] T. Nyokong, "Effects of substituents on the photochemical and photophysical properties of main group metal phthalocyanines," Coordination Chemistry Reviews, vol. 251, no. 1314, pp. 1707-1722, 2007.

[6] T. Pesha, G. R. Monama, M. J. Hato et al., "Inhibition effect of phthalocyaninatocopper (II) and 4-tetranitro (phthalocyaninato) copper (II) inhibitors for protection of aluminium in acidic media," International Journal of Electrochemical Science, vol. 14, pp. 137-149, 2019.

[7] F. Hashim, K. Al-Azawi, S. B. Al-Bghdadi, L. M. Shaker, and A. Al-Amiery, "Experimental and theoretical approach to the corrosion inhibition of mild steel in $\mathrm{HCl}$ solution by a newly coumarin," in Proceedings of the 23rd International Electronic Conference on Synthetic Organic Chemistry, vol. 41, no. 1, p. 15, New York, NY, USA, November 2019.

[8] M. Davoodi and M. Nasr-Esfahani, "Enhancement of the anticorrosion efficient of hybrid nanostructure coating using copper phthalocyanine self-assembled monolayers," Protection of Metals and Physical Chemistry of Surfaces, vol. 52, no. 1, pp. 149-155, 2016.

[9] N. N. C. Isa, Y. Mohd, M. H. M. Zaki, and S. A. S. Mohamad, "Characterization of copper coating electrodeposited on stainless steel substrate," International Journal of Electrochemical Science, vol. 12, pp. 6010-6021, 2017.
[10] S. R. Rusi and S. R. Majid, "Effects of electrodeposition mode and deposition cycle on the electrochemical performance of $\mathrm{MnO}_{2}-\mathrm{NiO}$ composite electrodes for high-energy-density supercapacitors," PLoS One, vol. 11, no. 5, Article ID e0154566, 2016.

[11] A. D. Jagadale, V. S. Kumbhar, and C. D. Lokhande, "Supercapacitive activities of potentiodynamically deposited nanoflakes of cobalt oxide $\left(\mathrm{Co}_{3} \mathrm{O}_{4}\right)$ thin film electrode," Journal of Colloid and Interface Science, vol. 406, pp. 225-230, 2013.

[12] N. Nnaji, N. Nwaji, G. Fomo, J. Mack, and T. Nyokong, "Inhibition of aluminium corrosion using benzothiazole and its phthalocyanine derivative," Electrocatalysis, vol. 10, no. 4, pp. 445-458, 2019.

[13] N. Nnaji, N. Nwaji, J. Mack, and T. Nyokong, "Corrosion resistance of aluminum against acid activation: impact of benzothiazole-substituted gallium phthalocyanine," Molecules, vol. 24, no. 1, p. 207, 2019.

[14] N. Nwaji, O. M. Bankole, J. Britton, and T. Nyokong, "Photophysical and nonlinear optical study of benzothiazole substituted phthalocyanines in solution and thin films," Journal of Porphyrins and Phthalocyanines, vol. 21, no. 4-6, pp. 263-272, 2017.

[15] A. Ramos, F. Nascimento, T. De Souza et al., "Photochemical and photophysical properties of phthalocyanines modified with optically active alcohols," Molecules, vol. 20, no. 8, pp. 13575-13590, 2015.

[16] M. A. Rauf, S. Hisaindee, J. P. Graham, and M. Nawaz, "Solvent effects on the absorption and fluorescence spectra of $\mathrm{Cu}$ (II)-phthalocyanine and DFT calculations," Journal of Molecular Liquids, vol. 168, pp. 102-109, 2012.

[17] R. Li, X. Zhang, P. Zhu, D. K. P. Ng, N. Kobayashi, and J. Jiang, "Electron-donating or-withdrawing nature of substituents revealed by the electrochemistry of metal-free phthalocyanines," Inorganic Chemistry, vol. 45, no. 5, pp. 2327-2334, 2006.

[18] T. Nyokong, "Electronic spectral and electrochemical behaviour of near infrared absorbing metallophthalocyanines," Structure and Bonding, vol. 135, pp. 45-87, 2010.

[19] L. H. Madkour and I. H. Elshamy, "Experimental and computational studies on the inhibition performances of benzimidazole and its derivatives for the corrosion of copper in nitric acid," International Journal of Industrial Chemistry, vol. 7, no. 2, pp. 195-221, 2016.

[20] J. E. Sturm, "Grid of expressions related to the einstein coefficients," Journal of Chemical Education, vol. 67, no. 1, pp. 32-33, 1990.

[21] A. M. Bond, K. B. Oldham, and C. G. Zoski, "Steady-state voltammetry," Analytica Chimica Acta, vol. 216, pp. 177-230, 1989.

[22] T. Nyokong, "Electrodes modified with monomeric M4catalysts for the detection of environmentally importantmolecules," in N4-acrocyclic Metal Complexes,J. H. Zagal, F. Bedioui, and J. P. Dodelet, Eds., Springer, New York, NY, USA, pp. 315-347, 2006.

[23] M. D. Maximino, C. S. Martin, M. S. Pereira, and P. Alessio, "Metallic phthalocyanines: impact of the film deposition method on its supramolecular arrangement and sensor performance," Annals of the Brazilian Academy of Sciences, vol. 91, no. 4, Article ID e20181201, 2019.

[24] M. Sivakumar, R. Subadevi, S. Rajendran, N.-L. Wu, and J.-Y. Lee, "Electrochemical studies on [(1-x) PVA- $x$ PMMA] Solid polymer blend electrolytes complexed with LiBF4," 
Materials Chemistry and Physics, vol. 97, no. 2-3, pp. 330-336, 2006.

[25] K. Vinothkumar and M. G. Sethuraman, "Protection of copper from corrosion through electrodeposited poly-2, 5dimercapto-1, 3, 4-thiadiazole- $\mathrm{TiO}_{2}$ composite film," Polymer Bulletin, 2020.

[26] S. M. Sayyah and R. E. Azooz, "Electrosynthesis and characterization of adherent poly (2-aminobenzothiazole) on Ptelectrode from acidic solution," Arabian Journal of Chemistry, vol. 9, no. 1, pp. S576-S586, 2016.

[27] K. Leetmaa, M. A. Gomez, L. Becze, F. Guo, and G. P. Demopoulos, "Comparative molecular characterization of aluminum hydroxy-gels derived from chloride and sulphate salts," Journal of Chemical Technology and Biotechnology, vol. 89, no. 2, pp. 206-213, 2014.

[28] A. Handy and N. S. El-Gendy, "Thermodynamic, adsorption and electrochemical studies for corrosion inhibition of carbon steel by henna extract in acid medium," Egyptian Journal of Petroleum, vol. 22, no. 1, pp. 17-25, 2013.

[29] K. A. Rodgers, M. R. Gregory, and R. Barton, "Bayerite, nordstrandite, gibbsite, brucite, and pseudoboehmite in discharged caustic waste from campbell island, southwest pacific," Clays and Clay Minerals, vol. 39, no. 1, pp. 103-107, 1991.

[30] T. Kozawa and M. Naito, "Mechanically induced formation of metastable $\chi$-and $\kappa-\mathrm{Al}_{2} \mathrm{O}_{3}$ from boehmite," Advanced Powder Technology, vol. 27, no. 3, pp. 935-939, 2016.

[31] D. Seifzadeh, A. Bezaatpour, and R. A. Joghani, "Corrosion inhibition effect of N, N'-bis (2-pyridylmethylidene)-1, 2diiminoethane on AZ91D magnesium alloy in acidic media," Transactions of Nonferrous Metals Society of China, vol. 24, no. 11, pp. 3441-3451, 2014.

[32] D. K. Verma and F. Khan, "Corrosion inhibition of mild steel in hydrochloric acid using extract of glycine max leaves," Research on Chemical Intermediates, vol. 42, no. 4, pp. 3489-3506, 2016.

[33] A. T. Ozyilmaz, M. Erbil, and B. Yazici, "The corrosion behaviours of polyaniline coated stainless steel in acidic solutions," Thin Solid Films, vol. 496, pp. 431-437, 2006.

[34] M. A. Amin, S. S. Abd El-Rehim, E. E. F. El-Sherbini, and R. S. Bayoumi, "The inhibition of low carbon steel corrosion in hydrochloric acid solutions by succinic acid," Electrochimica Acta, vol. 52, no. 11, pp. 3588-3600, 2007.

[35] N. Kuriakose, J. T. Kakkassery, V. P. Raphael, and S. K. Shanmughan, "Electrochemical impedance spectroscopy and potentiodynamic polarization analysis on anticorrosive activity of thiophene-2-carbaldehyde derivative in acid medium," Indian Journal of Materials Science, vol. 2014, Article ID 124065, 2014

[36] I. Ahamad, R. Prasad, and M. A. Quraishi, "Adsorption and inhibitive properties of some new Mannich bases of Isatin derivatives on corrosion of mild steel in acidic media," Corrosion Science, vol. 52, no. 4, pp. 1472-1481, 2010.

[37] H. Lu, Y. Zhou, S. Vongehr, K. Hu, and X. Meng, "Electropolymerization of PANI coating in nitric acid for corrosion protection of 430 SS," Synthetic Metals, vol. 161, no. 13-14, pp. 1368-1376, 2011.

[38] D. K. Lavanya, F. V. Priya, and D. P. Vijaya, "Green approach to corrosion inhibition of mild steel in hydrochloric acid by 1 [Morpholin-4-yl (thiophen-2-yl) methyl] thiourea," Journal of Failure Analysis and Prevention, vol. 20, no. 2, pp. 494-502, 2020.

[39] L. O. Olasunkanmi, I. B. Obot, and E. E. Ebenso, "Adsorption and corrosion inhibition properties of $\mathrm{N}-\{\mathrm{n}-[1-\mathrm{R}-5-$ (quinoxalin-6-yl) -4, 5-dihydropyrazol-3-yl] phenyl\} methanesulfonamides on mild steel in $1 \mathrm{M} \mathrm{HCl}$ : experimental and theoretical studies," RSC Advances, vol. 6, no. 90, pp. 86782-86797, 2016.

[40] K. Shahzad, M. H. Sliem, R. A. Shakoor et al., "Electrochemical and thermodynamic study on the corrosion performance of API X120 steel in $3.5 \% \mathrm{NaCl}$ solution," Science Reports, vol. 10, no. 1, p. 4314, 2020.

[41] A. Ganash, "Effect of current density on the corrosion protection of poly (otoluidine)-coated stainless steel," International Journal of Electrochemical Science, vol. 9, no. 7, pp. 4000-4013, 2014. 